\title{
Analysis on stress state of box-girder web under prestressing effect
}

\author{
Haijun Yin ${ }^{1,2}$, Ziqing $\mathrm{Li}^{1}$,Xianwu Hao ${ }^{1}$,Baojun Zhao ${ }^{3}$ \\ ${ }^{1}$ School of highway Engineering, Chang'an University, Xi'an 710064, China; \\ ${ }^{2}$ Xi' an Architecture \& Technology University, Xi'an 710055,China; \\ ${ }^{3}$ Shaanxi Provincial Communication Construction Group, Xi' an 710075, China
}

\begin{abstract}
In order to study the effect of prestressed box girder webs stresss state, determining the stress distribution within a web, research and analysis of vertical prestressed box girder, curved beam prestressed sensitivity under the web. Establishing the finite element model of the box girder web vertical prestressing effect is analyzed, results show that the principal tensile stress of the web is sensitive to the vertical prestress, applying the vertical prestress can effectively reduce the principal tensile stress of the web; with the decrease of the effective vertical prestress, the neutral axis above the principal compressive stress decreases rapidly, while below the neutral axis decreases relatively slow; Under the same vertical preloading stress level, the roots of cross section of the compressive stress of web reserves than L / 4 section of the web. Calculation and analysis of curved beam under bending point, different bending angles and bending radius of principal stress effect on the web, Results show that the set of curved beam web when the curved beam bending stress concentration easily, appear the main tensile stress; Increase the bending radius can effectively reduce beam cross-section of web principal tensile stress, along with the rising of the next corner, principal tensile stress peak value increases gradually, thus setting bending beam, should try to reduce the bending angle.
\end{abstract}

\section{Analysis of the vertical prestress influence}

Vertical prestress can effectively resist the main tensile stress and shear stress of the box girder. But some of the bridge cracks are still common even though the web has vertical prestress. One of the main causes of this problem is the loss of vertical prestress. The vertical prestress of some bridges may even lose more than half [6], which is very detrimental to the force of the box. In order to explore the impact of vertical prestress on the fracture of the peritoneal plate of the box girder, ANSYS, a finite element software, was used to analyze the sensitivity of the vertical prestress effect of the girder. Due to the structure and load symmetry, take a quarter of the real bridge modeling, SOLID45 unit are adopted to simulate the concrete and LINK8 element to simulate prestressed reinforcement, the prestress effect is included in the equivalent load, and the calculation model is shown in figure 1.There are four kinds of calculation conditions:

Working condition 1: the effective vertical prestress is accounted for $100 \%$ of tension control;

Working condition 2: the effective vertical prestress is accounted for $60 \%$ of tension control; 
Working condition 3: effective vertical prestress is accounted for $30 \%$ of tension control;

Working condition 4: excluding vertical prestress.

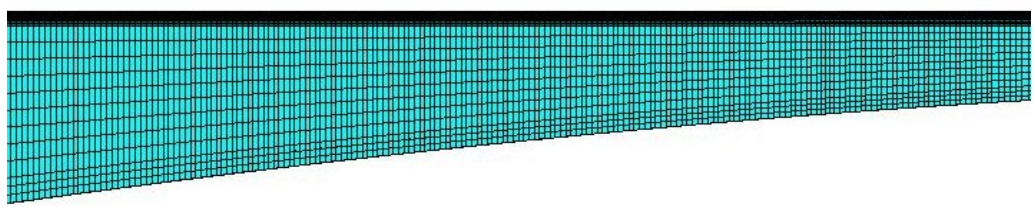

Figure .1 Local Calculation Model

The main stress of the two sections of the box girder section 2 of the root and the $1 / 4$ sections are drawn in figure 2.Figure 3 shows the main stress vector diagram of the box girder in the area near the L/4 cross section of the bridge under different working conditions.

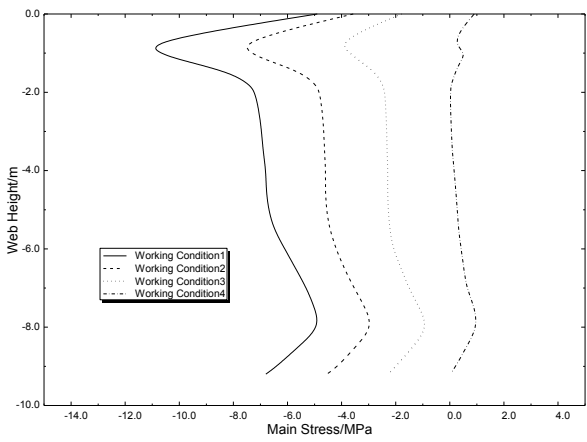

(a) Section 2 of the Root

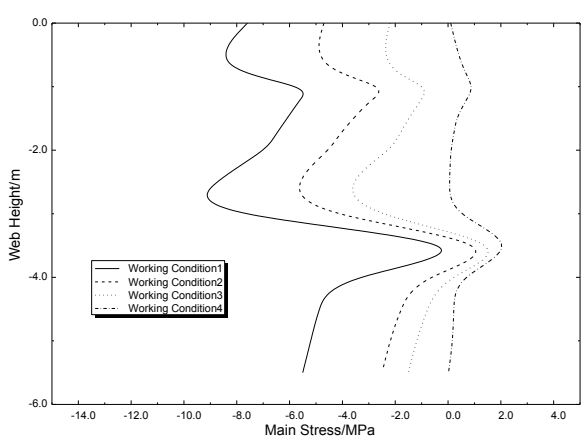

(b) $1 / 4$ Cross Section

Figure .2 Comparison of Principal Stress in Each Working Condition

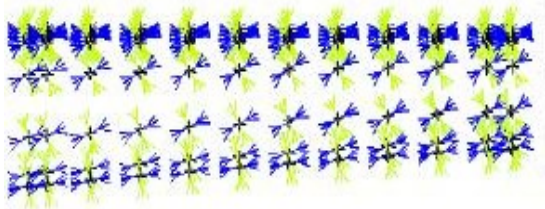

(a) Working Condition 1-3

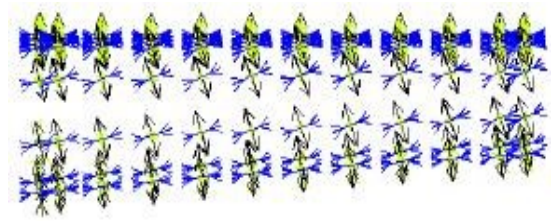

(b) Working Condition 4

Figure .3 Main Stress Vector Diagram of Vertical Web under Different Working conditions

The calculation results show that: (1) The main tensile stress of the web is more sensitive to the vertical prestress, and the vertical stress can be applied to reduce the tensile stress. (2) When the effective vertical prestress is kept at more than $60 \%$, the minimum principal stress is basically above $2.0 \mathrm{Mpa}$, so the calculation formula of vertical prestress in the specification is reasonable by multiplying the reduction factor of 0.6. (3) With the decrease of the effective vertical prestress, the main compressive stress above the neutral axis of the abdominal plate decreases faster, while the lower part of the neutral axis decreases slower. (4) In the condition of excluding vertical prestress, The main tensile stress is generated along the entire cross-section of the abdominal plate, If the stress loss of prestressed tendon and the shrinkage creep effect of concrete are considered, the main tensile stress may exceed the limit, which will cause the web to crack. Therefore, the vertical prestress setting is necessary.(5) In contrast, under the same vertical preloading 
stress level, the root section of the web compressive stress reserves bigger than $\mathrm{L} / 4$ section of the web. In other words, L/4 section web easier to crack, the box girder web plate cracking phenomenon is consistent with engineering practice [7] [8].

\section{Analysis of the influence of downward bending beams of the web}

\subsection{The stress of web sensitivity analysis of the downward bending beams}

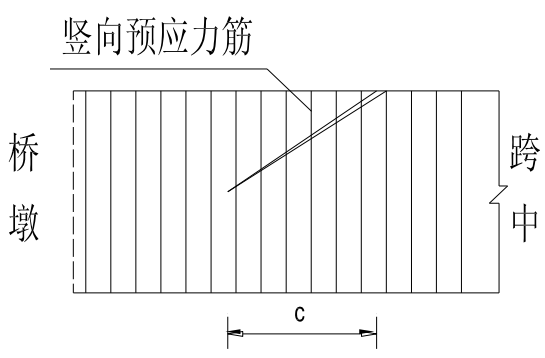

(a) Without Downward Hending Beam

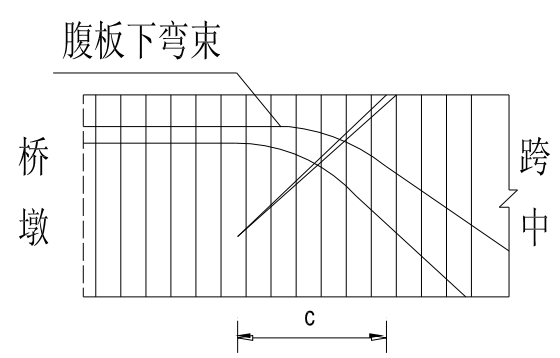

(b) Set Downward Bending Beam

Figure 4 A Diagram of the Layout of Prestressed Tendons in Continuous Rigid Frame Bridges

In the way of prestressed reinforcement arrangement in the large span PC box girder bridge, there are two kinds of fabric reinforcement (see Figure 4) under which the bending beam is set and the bending beam is not set. It is easy to construct the rigid frame bridge with the longitudinal prestressing and vertical prestressing to overcome the main tensile stress. The box girder with bending beam can effectively improve the stress state of the web and overcome the fracture of the abdominal plate caused by the main tensile stress [9].

Taking the background bridge as an example, two kinds of bridge models are established, which are to cancel the downward bending beams and to set the downward bending beams. In order to analyze the influence degree of the downward bending beam to the web stress, we choose the A section of control section 141 main pier to calculate (see Figure 5), and analyze the stress change of two schemes along the box girder in the finished state.

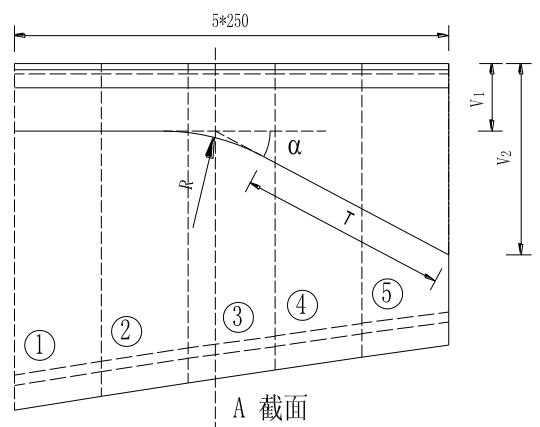

Figure 5 The Calculated Section

Figure 6 is the contrast diagram of the height stress variation along the box girder at the A section of the 141 main pier with two kinds of reinforcement. The longitudinal coordinates in the diagram represent a change along the height of the web, the unit is $\mathrm{m}$; the 
negative value of the abscissa represents the compressive stress, and the positive value represents the tensile stress, and the unit is $\mathrm{MPa}$.

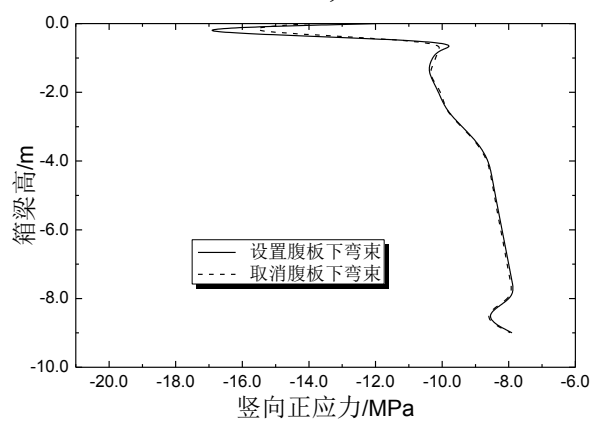

(a) Longitudinal positive stress

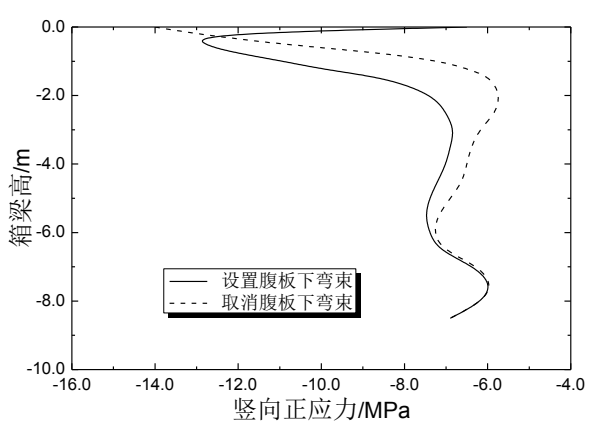

(b) Vertical positive stress

The results show that: (1) Bending beam has less influence on longitudinal normal stress of box girder, but the peak of stress changes sharply in the roof straight-beam anchorage. The reason is that the horizontal component of bending beam strengthens the longitudinal stress of box beam; (2) The influence of the bending beam on the vertical normal stress of the box girder decreases from the upper part to the lower part of the box girder; (3) The adown bending beam can effectively reduce the main tensile stress of the web, The main tensile stress is greatly reduced, less impact on the part below the centroid of the web.

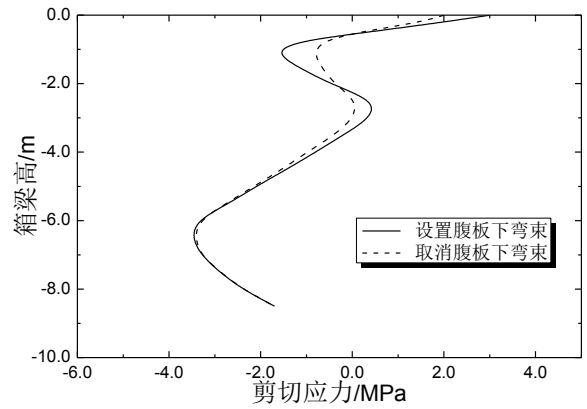

(c) Shear Stress

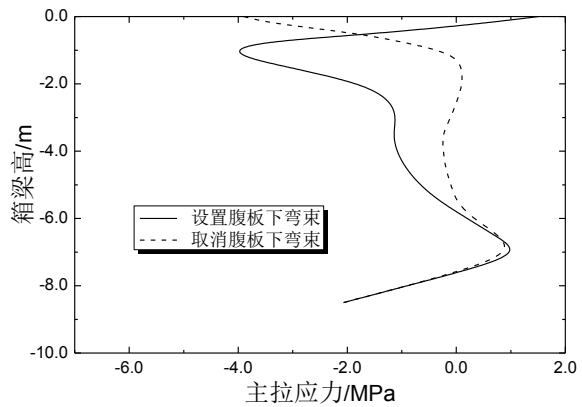

(d) Principal Stress

Figure. 6 Comparison of the stress of A cross section of the Box Girder in Two kinds of Reinforcement

Therefore,compared with the set of Web bending beam with beam scheme, cancellation of web bending beam, in the A section near the root of the box girder, box girder along the height direction of the principal compressive stress decreases, and in the area above the center of the web, the principal tensile stress increases obviously and easily overrun, cause cracking in webs[11].

\subsection{Analysis of the influence of downward bending beam on the slanting cracks of box girder web}

In the cantilever construction of PC box girder webs, oblique cracks parallelled to the bending beam are usually appeared. The laws of fracture crack mechanism, location, direction and distribution reflect that the cracks are generated during the bending of the lower bending beam Caused by the radial force [6] (Figure 7) 


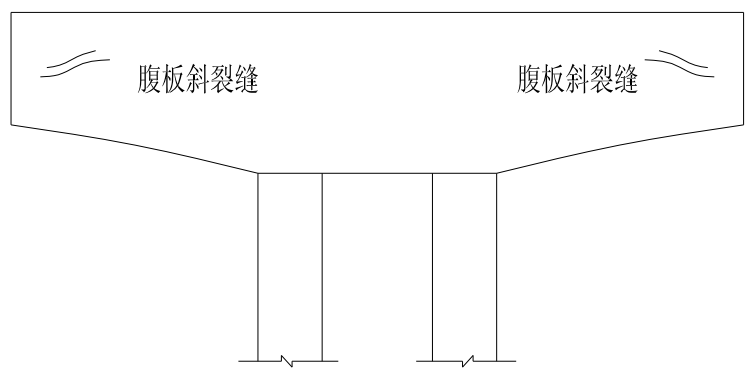

Figure. 7 The Slanting Cracks of Box Girder Web

(1) Analytic solution

The radial distribution force of the radial core to the concrete is generated within the curve range after the adown bending beams of the web are stretched. (Fig. 8), $q=P / R$, the effective preload is $\mathrm{P}$, the radius of the web beams is $\mathrm{R}$ [12].

Set,

$$
\left\{\begin{array}{l}
X=\cos \alpha \\
Y=\sin \alpha
\end{array}\right.
$$

According to the balance of vertical force on the curve $\sum Y=0$,it is obtained,

$$
\int_{S} q \cos \alpha d s=\Delta F_{y}
$$

That is,

$$
\begin{gathered}
\int_{\theta_{1}}^{\theta_{2}} q R \cos \alpha d \alpha=P_{2} \sin \theta_{2}-P_{1} \sin \theta_{1} \\
q=\frac{P_{2} \sin \theta_{2}-P_{1} \sin \theta_{1}}{R\left(\sin \theta_{2}-\sin \theta_{1}\right)}
\end{gathered}
$$

Where, $\mathrm{P}$ is radial force; $\mathrm{T}$ is tension of prestressed tendons; $\theta$ is bending angle of prestressed tendons; $\mathrm{R}$ is radius of curvature.
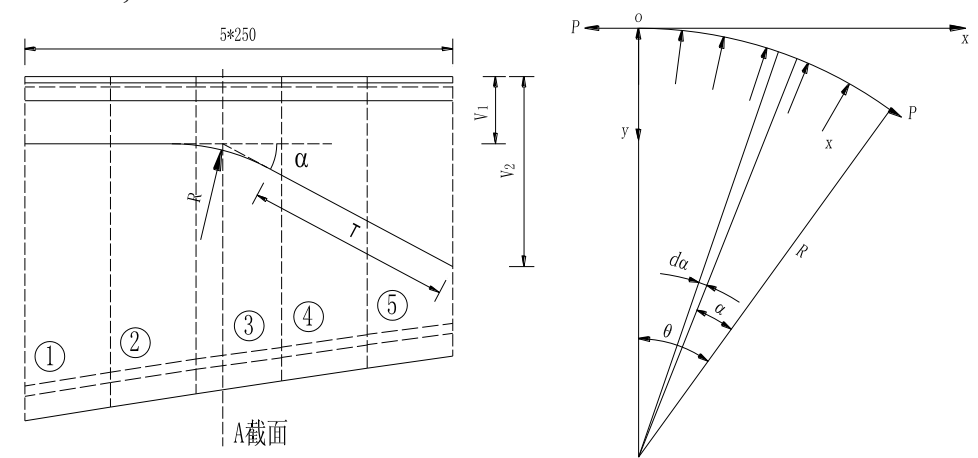

Figure 8 The Radial Force Caused by Downward Bending Beam

(2) Numerical solution

In this paper, ANSYS finite element software is used to calculate the influence of different downward bending beams on the main stress of the web. In the calculation analysis, the influence of bending point, bending angle and bending radius of the downward 
bending beam in the web is considered, and a total of 6 calculation models are given, and the calculation parameters are shown in Table 1.

Table 1 The Calculation Parameters

\begin{tabular}{|c|c|c|c|c|c|}
\hline Model & $R(m)$ & $\alpha^{\circ}$ & $T(m)$ & $V_{1}(m)$ & $V_{2}(m)$ \\
\hline 1 & 6.0 & $27.98^{\circ}$ & 6.113 & 4.73 & 1.37 \\
\hline 2 & 8.0 & $27.98^{\circ}$ & 5.615 & 4.73 & 1.37 \\
\hline 3 & 10.0 & $27.98^{\circ}$ & 5.117 & 4.73 & 1.37 \\
\hline 4 & 12.0 & $27.98^{\circ}$ & 4.618 & 4.73 & 1.37 \\
\hline 5 & 10.0 & $17.43^{\circ}$ & 5.509 & 4.06 & 1.37 \\
\hline 6 & 10.0 & $36.81^{\circ}$ & 5.064 & 6.978 & 1.37 \\
\hline
\end{tabular}

The concrete of the web is simulated by SOLID45 element, in which elastic modulus is $E=3.35 \times 10^{4} \mathrm{MPa}$, the downward bending beam in the web is chosen to simulate with LINK8 element, the Poisson's ratio is 0.3 , the bending curve of the lower beam is simulated according to the actual line shape, without considering the role of transverse prestress and the vertical prestress. The finite element model and the calculation results are shown in Figure 10 to 12 .

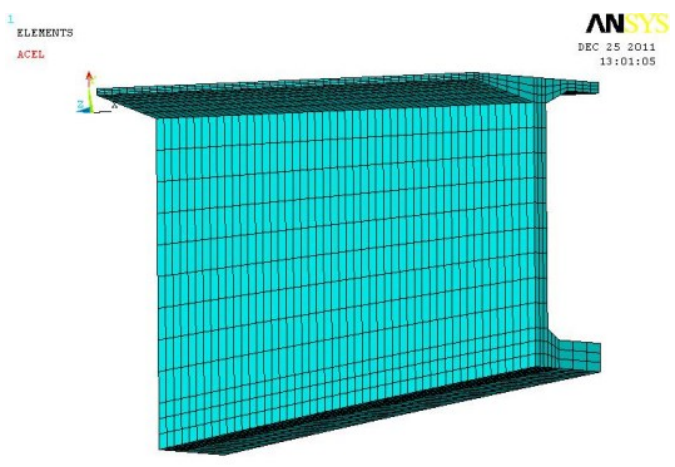

Figure10 Finite element Model

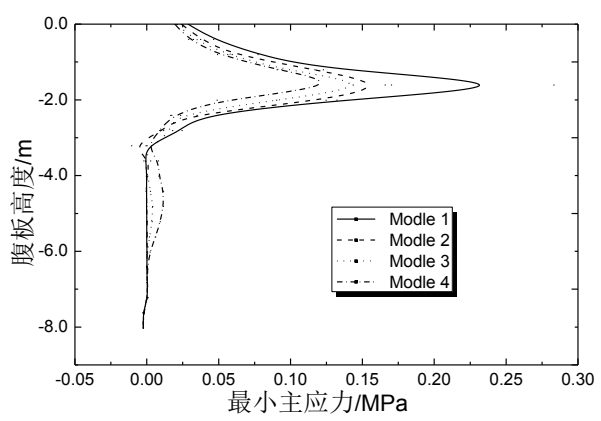

(a) Different bending radius

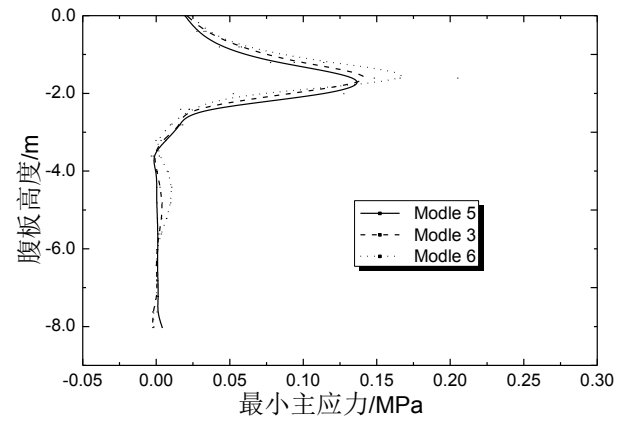

(b) Different bending angle 
Figure 11 Comparison of minimum principal stress (principal tensile stress) of section A of web under different conditions

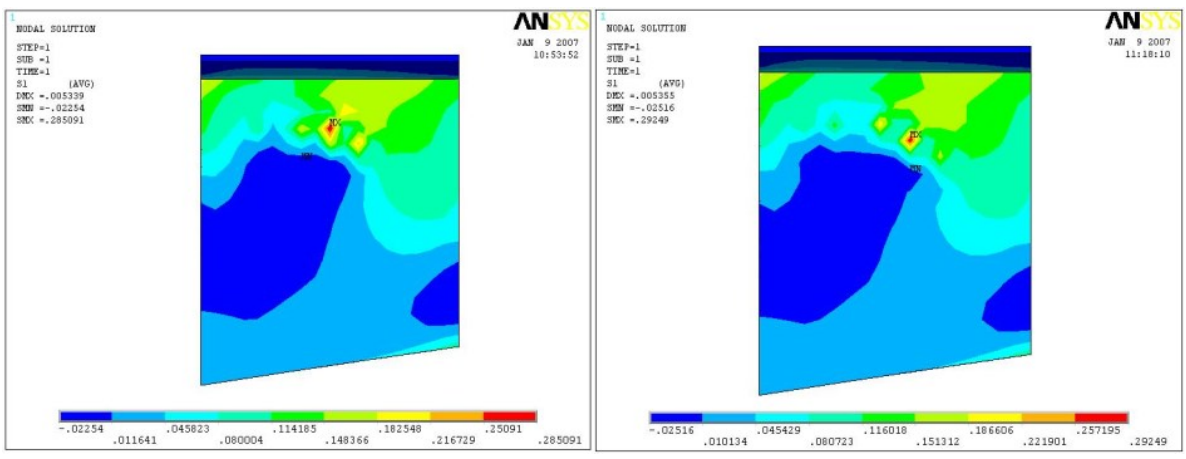

(a) Principal stress cloud diagram of Model 1

(b) Principal stress cloud diagram of Model 2

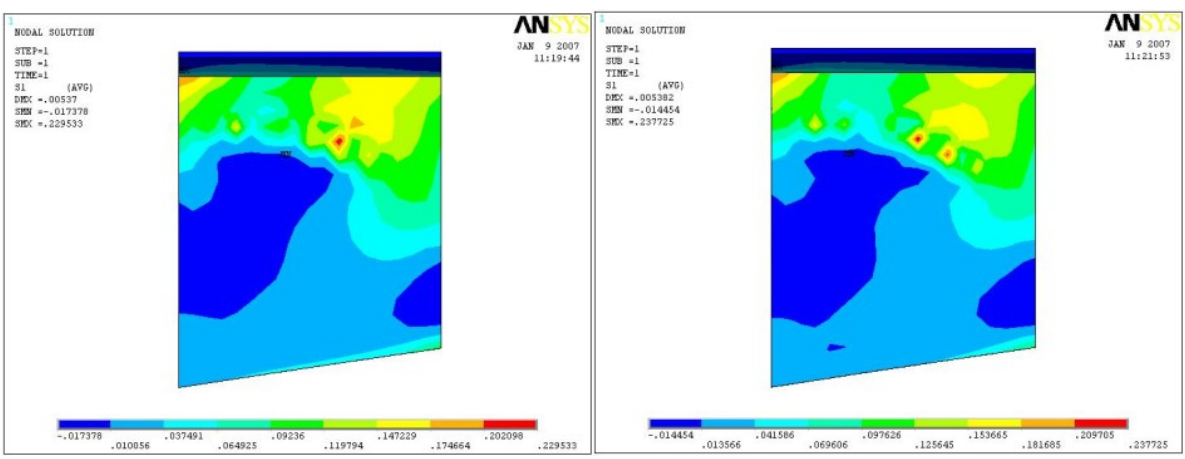

(a) Principal stress cloud diagram of Model 3

(b) Principal stress cloud diagram of Model 4
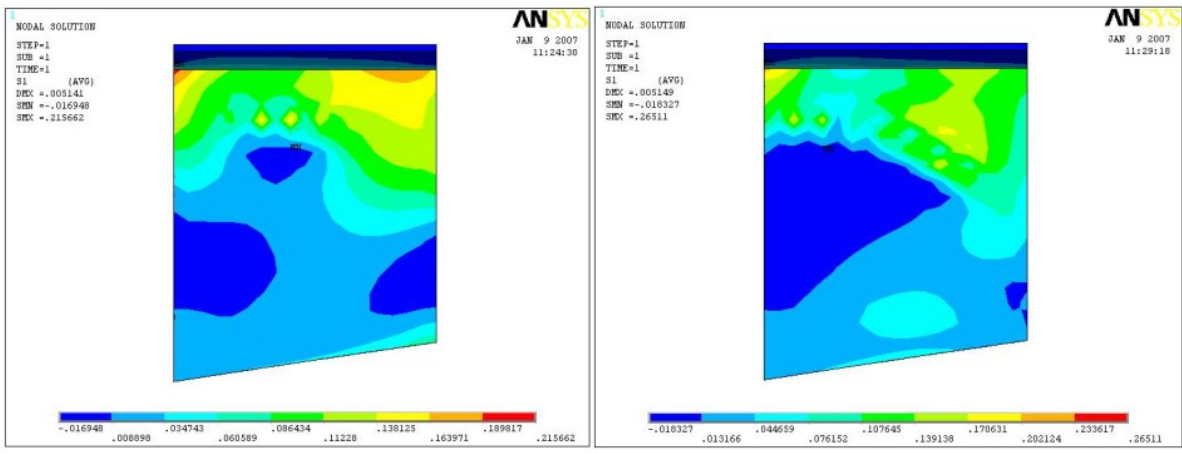

(a) Principal stress cloud diagram of Model 5

(b) Principal stress cloud diagram of Model 6

Figure 12 The main stress of the web under each condition cloud diagram

The calculation results show that: (1) when the downwards bending beam is set in the web, the stress concentration is easy to occur at the bend of the bending beam and the main tensile stress appears. (2) Compared with Modle1 to Modle4, the main tensile stress decreases from $0.28 \mathrm{MPa}$ to $0.14 \mathrm{MPa}$. Increasing the bending radius can effectively reduce the principal tensile stress at the web beam cross section. From Modle5, Modle 3 and Modle6, it can be seen that as the lower corner increases, the peak value of the main tensile stress increases from $0.13 \mathrm{MPa}$ to $0.20 \mathrm{MPa}$. Therefore, when setting the lower corner 
beam, the cornering angle should be minimized. (3) The diagonal cracks appearing along the direction of the web beam layout have a limited impact on the bridge structure and will be automatically closed during the bridge's operation. Therefore, it is only necessary to seal the diagonal cracks [6] [13].

\section{Conclusion}

(1) The main tensile stress of the abdominal plate is more sensitive to the vertical prestress, and the vertical prestress can be applied to reduce the stress of the main plate.

(2) When the effective vertical prestress is kept at more than $60 \%$, the minimum principal stress is basically above $2.0 \mathrm{Mpa}$, so the calculation formula of vertical prestress in the specification is reasonable by multiplying the reduction factor of 0.6 .

(3) With the decrease of the effective vertical prestress, the main compressive stress above the neutral axis of the abdominal plate decreases faster, while the lower part of the neutral axis decreases slower.

(4)In contrast, under the same vertical preloading stress level, the root section of the web compressive stress reserves bigger than L/4 section of the web. In other words, L/4 section web easier to crack, the box girder web plate cracking phenomenon is consistent with engineering practice.

(5) When the bending beam is set under the web, the stress concentration is easy to be concentrated in the bending bend at the next bend. Increasing the bending radius can effectively reduce the principal tensile stress at the web beam cross section. As the lower corner increases, the peak value of the main tensile stress increases. Therefore, when setting the lower corner beam, the cornering angle should be minimized.

(6) The diagonal cracks appearing along the direction of the web beam layout have a limited impact on the bridge structure and will be automatically closed during the bridge's operation. Therefore, it is only necessary to seal the diagonal cracks.

\section{References}

1 .Lou zhuang hong. The fracture of prestressed beam bridge [J]. Highway traffic technology, 2000, 12 (6):49-52.

2 .Lu jianming, Chen ke. Analysis of the main stress of prestressed concrete box girder web [J]. Highway traffic technology, 2005, 22(10): 51-55.

3. Peng wei, hongyan, ke shangang et al. Research on fracture control of PC continuous box girder bridge [J]. Journal of zhejiang university of technology, 2003, 1: 22-27.

4. Zhao baojun, Yin hai-jun, hao xianwu, meng jiang. Test analysis of vertical prestress diffusion effect of PC box girder web. [J]. Civil architecture and environmental engineering.

5. Li bin. A study on the vertical prestress of the web of the box girder with the secondary tensioning of steel wire. [D]. Master's thesis. Hunan University. 2009.

6. Xiao xing. Analysis of the causes of the oblique fracture of the web in the construction of prestressed concrete box girder Bridges [J]. Modern transportation technology, 2007, 4 (1):43-47.

7. Yan fanghua. The setting analysis of bending beam under the web of continuous box girder with cantilevered cantilever [J]. Northern traffic, 2007, 12 (12)

8. Christopher J Waldron.Investigation of Long-term Prestress Losses in Pretensioned High Performance Concrete Girders [D].American: The Virginia Polytechnic Institute and State University, 2004, 1-206. 
9. Zhong xingu, li feng, zou jianmin et al. Analysis of the stress of the abdominal plate under the vertical prestress of concrete box girder Bridges [J]. Journal of hunan university of science and technology, 2005, 20 (2): 48-52.

10. Shao xudong, li bin, zeng tiansheng. The calculation and measurement of the stress field of the prestressed steel strand of the low retraction prestressed steel wires applied to the vertical prestress of the web [J]. Highway traffic technology. 2009, 9(9).

11. Tadros M.K.,Al-Omaishi,N.,Seguirant,S.J.Prestress Losses in Pretensioned HighStrength Concrete Bridge Girders. National Cooperative Highway Research Program Report [J], Transportation Research Board, National Research Council, 2003.

12. Yan donghuang, Lin Ming, yuan Ming. Analysis on the elastic compression loss of the vertical prestressed tendon of concrete box girder.

13. H.Broo,Lundgren,B.Engstrom. Shear and torsion interaetion in prestressed hollow core unit s [J].Magazine of Conerete Researeh, 2005, 57(9):521-533. 